This PDF is a selection from a published volume from the National Bureau of Economic Research

Volume Title: Hard-to-Measure Goods and Services: Essays in Honor of Zvi Griliches

Volume Author/Editor: Ernst R. Berndt and Charles R. Hulten, editors

Volume Publisher: University of Chicago Press

Volume ISBN: 0-226-04449-1; 978-0-226-04449-1

Volume URL: http://www.nber.org/books/bern07-1

Conference Date: September 19-20, 2003

Publication Date: October 2007

Title: Computer Input, Computer Networks, and Productivity

Author: B. K. Atrostic, Sang Nguyen

URL: http://www.nber.org/chapters/c0884 


\section{Computer Input, Computer Networks, and Productivity}

B. K. Atrostic and Sang Nguyen

\subsection{Introduction}

Computer networks may be a new technology that shifts the production function. Our previous research (Atrostic and Nguyen 2005) found a positive and significant relationship between computer networks and labor productivity in U.S. manufacturing, using the first survey data on the presence of computer networks in manufacturing plants, collected in the 1999 Computer Network Use Survey (CNUS). We controlled for other inputs to production, plant characteristics, and the endogeneity of computer networks. However, because no data to proxy for the capital stocks of computers were available, our previous estimate of the relationship between computer networks and plants' labor productivity may be subject to an omitted variable bias.

This paper extends our previous model to include computer capital as a separate input in the production function. We use new plant-level data on computer investment from the 2000 Annual Survey of Manufactures (ASM) to develop a proxy for computer capital input. An important con-

B. K. Atrostic is a senior economist at the Center for Economic Studies at the U.S. Census Bureau. Sang Nguyen is a senior economist at the Center for Economic Studies at the U.S. Census Bureau.

This paper reports the results of research and analysis undertaken by the authors. It has undergone a more limited review than official publications. Opinions expressed are those of the authors and do not necessarily represent the official position of the U.S. Census Bureau. This report is distributed to inform interested parties of research and to encourage discussion.

We have benefited from comments by Randy Becker and Jack Triplett; Mark Roberts, the editors, and other participants at the NBER Conference on Research in Income and Wealth on Hard-to-Measure Goods and Services: Essays in Memory of Zvi Griliches; seminar participants at the National Institute for Social and Economic Research, London, England, March 2004; and the referees; but all errors are, of course, the authors' own. 
tribution of this paper is to define the sample for which the measures of computer and conventional physical capital available in the data-computer investment and book value-are good proxies for these inputs. We show that these measures are good proxies only for plants that are new. For new plants, computer investment should equal the value of the plant's computer stock, and book values of buildings and machinery equal the value of the plant's physical capital stock.

We create a sample of new plants with the best proxies possible with the available data. Using this sample, we find positive and significant relationships between labor productivity and both computer networks and computer capital inputs. Our findings suggest that understanding the relationship between computers and productivity requires measures of how businesses use computers.

\subsection{Computers, Computer Networks, and Productivity: Measurement Issues}

Estimating plant-level relationships among computers, computer networks, and productivity requires overcoming many empirical challenges. Researchers must address the substantial standard measurement issues that arise in using plant-level data (see Griliches 1994; Griliches and Mairesse 1995). Serious data gaps specific to the quest to understand the economic role of computers, electronic devices, and computer networks plague the resulting empirical literature on computers and productivity (see, for example, Atrostic, Gates, and Jarmin 2000; Haltiwanger and Jar$\min 2000$ ). These gaps likely contribute to its divergent findings on data issues (Stiroh 2004). In this section, we focus on three specific measurement issues - measuring capital inputs in general, measuring computer inputs, and defining a sample with good measures of both - and on using that sample to estimate the relationship between computer networks and productivity.

\subsubsection{Measuring Capital Input}

Our productivity model requires a measure of capital inputs or capital services. Such a measure, or the data needed to create it, is hard to get directly. Researchers have developed ways to use the information that is typically available to create proxies for capital inputs that are widely used in both time series and cross-section analyses. However, our data lack the information needed to create these standard proxies.

For time series analysis, a measure of capital services can be generated from information on the capital stock. The perpetual inventory method usually builds the capital measure up from data on capital investments, depreciation, and asset prices. That is, $K_{t}=K_{0}+\Sigma \Delta K^{\tau}(\tau=0, \ldots, \tau-1)$, where $\Delta K^{\tau}=\left(I_{t}-D_{t}\right) / P_{t}$ and $I, D$, and $P$ denote capital investments, depre- 
ciation, and asset prices. A problem with the perpetual inventory method, especially at the plant level, is the lack of plant-level data on depreciation and asset prices.

An alternative method uses the book value of capital as a proxy for the capital stock. An advantage of this approach is that book values are frequently collected directly from respondents. A major shortcoming of book values is that they are evaluated at the purchase prices, regardless of when the capital good was bought. Book values therefore reflect the true value of capital stocks only for special cases. ${ }^{1}$

The plant-level study by Baily, Hulten, and Campbell (1992) finds that both perpetual inventory and book value measures lead to similar empirical results for topics such as productivity dispersion. Doms (1996) also finds that book values and service flows measures yield similar results for a specific set of advanced technologies. Because of these empirical regularities, many researchers using plant-level data (e.g., Doms, Dunne, and Troske 1997; McGuckin, Streitwieser, and Doms 1998; Dunne et al. 2000; Greenan, Mairesse, and Topiol-Bensaid 2001) use the book values of the plant's total capital stock directly as a proxy for service flows. Stiroh's recent analysis (2004) also finds little empirical difference between the two measures.

For cross-section analysis, it is often impossible to construct a measure of capital services using the perpetual inventory method because the necessary time series of capital investment data are not available. Empirical cross-section studies often use book values of the capital stock as a proxy for capital services. Using book values requires assuming capital input is proportional to book values. This assumption may be correct if all plants in the sample have the same age. But this is not likely to be the case. Because book values are evaluated at the purchase price and plants in the sample differ in ages, book values of capital seriously mismeasure the plant's capital inputs.

Data gaps for recent years make it more difficult to use either perpetual inventory or book value measures of capital (see table 13A.1). Book values of physical capital (buildings and machinery) are now collected less frequently in U.S. manufacturing and for a smaller group of plants. Book values were collected annually in both the Census of Manufactures (CM) and ASM until 1986. Since then, these data are collected only in the Economic Census years (e.g., 1987, 1992, and 1997), and are collected only for the plants that are in the ASM sample in those years. The ASM sample is roughly 55,000 plants, far smaller than the roughly 350,000 plants in the 1997 CM (U.S. Census Bureau 2001).

1. To alleviate this problem, researchers often use plant ages and other plant characteristics as controls in their regression models when using book values as a proxy for capital inputs. 


\subsubsection{Measuring Computer Input}

Computers should be treated as a separate input in production and productivity analysis, as suggested by studies such as Jorgenson and Stiroh (2000) and Oliner and Sichel (2000). Computer services are the theoretically appropriate measure of computer input. Computer services, like other capital services, are not observed, and measures approximating this service flow must be constructed. Computer service flows are normally estimated from measures of the computer capital stock in aggregate and industry-level productivity studies (e.g., Jorgenson, Ho, and Stiroh 2005; Triplett and Bosworth 2003). However, book values of computer capital are not collected in government data, so studies using plant-level data often approximate computer service flows with measures of computer investment.

Investment has been used as a measure of the presence of computers, or of computer intensity, or as a measure of the intensity of technology use in many recent plant-level studies. Computer investment is used as a proxy for computer input in the plant in Berman, Bound, and Griliches (1994). Doms, Dunne, and Troske (1997) control for computer investment in their analysis of how adopting various technologies affects a series of plant-level economic outcomes. Dunne et al. (2000) examine the role of computer investment in the dispersion of productivity and wages in U.S. manufacturing. Haltiwanger, Jarmin, and Schank (2003) use computer investment as a factor separate from total equipment investment in estimating productivity.

Computer investment is a good proxy for computer capital stock under the assumption that this investment is equal or proportional to a plant's stock of computer capital. This assumption allows researchers to use the only measure at hand. However, it may not be correct. Total plant-level investment typically is lumpy, while service flows are not. Cooper, Haltiwanger, and Power (1999) find that plant-level investment surges are followed by periods of low investment. Becker et al. (2004) look at more recent data and find investment spikes in both firm- and plant-level data for investment in general. Recent research by Wilson (2004) suggests that firmlevel investment may be lumpy across specific kinds of investment, including computers and communications equipment. However, this result is based on the single available cross section of detailed investment data, so the lumpiness of investment can only be defined in terms of the share of a firm's investment in specific kinds of capital goods, rather than variation over time in the amount and kind of investment.

Actual investment to make computers usable in the workplace (coinvention) may be less lumpy than measured computer equipment investment. Coinvention includes expenditures developing and implementing software that engages and connects computers and adapts them to plant-specific 
uses, for example, Bresnahan and Greenstein (1997), as well as changes in workplace organization, management, and other organizational capital that make more effective use of computers, labor, and other inputs, for example, Brynjolfsson and Hitt (2003). Some of these expenditures may be capitalized, but others may be expensed. Coinvention may continue in periods when there is no investment in computer hardware and software. Because the scale of coinvention over the life of the computer asset can be as much as the original computer equipment investment (Bresnahan and Greenstein 1997), or up to ten times the investment in computer hardware (Brynjolfsson and Hitt 2003), the joint effect may be to smooth or exacerbate investment lumpiness. These unmeasured complementary computer investments may cause estimated returns to measured computer investments to exceed actual returns to measured computer investments, particularly in the long run (e.g., Brynjolfsson and Hitt 2003). However, any effect of coinvention on actual computer investment will not be captured in our measure because only data for investments in computer hardware and peripherals are collected in the 2000 ASM.

Data gaps for recent years also limit the available computer investment data. These data are collected only occasionally and in recent years were not collected at the same time as book values of capital. While computer investment data were collected in the CM for 1977 through 1992, they were not collected at all in 1997 (when book values of physical capital were collected) and were only collected again in the ASM in 2000 and 2001 (when book values of physical capital were not collected). The lumpiness of plantand firm-level investment means that investment data for a single year are not a good proxy for the plant's (or firm's) stock, except for new plants. In a new plant, capital investment would be equal to the value of the plant's capital stock.

\subsubsection{Developing a Sample with Good Proxies for Computer and Capital Inputs}

The data gaps for recent years make it difficult to argue that the data we have available on book values of capital and computer investment provide equally plausible proxies for total capital and computer services for all plants that responded to the CNUS. In this paper, we develop the best sample of CNUS respondents that our measures of computer and total capital allow us to make: a sample of plants that first appeared in the 1997 CM. When a plant is new, the book values of physical capital (buildings and machinery) and computer investment should equal the value of the plant's capital stock and the plant's computer capital stock, respectively.

If we were estimating productivity in 1997, it would be straightforward to use the book values of total capital that these new plants report in the 1997 CM as a proxy for their total capital services in 1997, making the standard assumption that capital services are proportional to the value of the 
capital stock. That is, for physical capital, $K_{T 1997} \equiv \mathrm{BV}_{T 1997}$, where $K$ is the value of the plant's total physical capital stock, $T$ indexes total capital, and $\mathrm{BV}$ is book value. ${ }^{2}$ However, we estimate productivity in 2000 (rather than 1997) because computer capital input is measured in 2000, and most of the remaining variables, particularly the variable of interest, computer networks, are measured in $1999 .{ }^{3}$ We therefore use standard capital theory to relate the flow of total capital services in $2000, S_{T}\left(K_{T 2000}\right)$, to total book value in 1997 for our sample of plants new in 1997:

$$
S_{T}\left(K_{T 2000}\right) \approx \pi_{T} \cdot \mathrm{BV}_{T 1997} \cdot \delta_{T \tau} .
$$

The proportionality factor, $\pi_{T}$, represents services per unit of total capital. The approximation error, $\delta_{T \tau}$, increases as 1997 differs from the year for which we wish to measure capital services. That is, $\delta_{T \tau}>\delta_{T v}$ when $\mid \tau-$ $1997|>| v-1997 \mid$ for plants observed in year $\tau$ compared to year $v$.

For computer capital stock in 2000, we use computer investment in 2000 as a proxy under the assumption that the total computer capital stock is proportional to observed investment:

$$
K_{C 2000} \approx \gamma \cdot I_{C 2000},
$$

where $K_{C 2000}$ represents the plant's actual computer capital stock, and $I_{C 2000}$ is the plant's computer investment in 2000. The proportionality factor, $\gamma$, is positive $(\gamma \geq 0)$ and assumed to be the same for all plants in our sample because they opened in the same year, 1997. If $\gamma=1$, the plant completely replaces its old computing stock with new computers.

We again use standard capital theory to relate the flow of computer capital services in $2000, S_{C}\left(K_{C 2000}\right)$, to our proxy for the computer capital stock:

$$
S_{C}\left(K_{C 2000}\right) \approx \pi_{C} \cdot I_{C 2000} \cdot \delta_{C \tau},
$$

2. We first link all observations that have both information on computer networks in the 1999 CNUS and information on computer investment in the 2000 ASM. Because the 1999 CNUS and 2000 ASM samples each are drawn from a sample frame based on the $1997 \mathrm{CM}$, the probability-proportionate-to-size sampling strategy leads to a high overlap between the two samples, and the 1999-2000 linking rate is high. Haltiwanger, Jarmin, and Schank (2003) find little sample reduction when they link the 1999 CNUS and the 2000 ASM. Their final sizes range from 22,700 to 22,900 , depending on specification. Because the data as entered in the CES data storage system do not allow us to distinguish between plants that do not report computer investment and those that report zero, we exclude both. This means that the plants in our sample all have positive computer investment. We find that roughly one-third of the linked plants report positive computer investment. This response pattern is consistent with the historical pattern when this item was collected in 1977, 1982, 1987, and 1992 (e.g., Dunne et al. 2000). From the linked sample we select plants that first appeared in the $1997 \mathrm{CM}$ (that is, they did not appear in the 1992 CM or the 1993 through 1996 ASMs).

3. Because computer networks are major investments and U.S. manufacturing plants have used some form of networks for decades, it seems reasonable to assume that plants with networks in 1999 will continue to have networks in 2000. 
where the proportionality factor, $\pi_{C}$, represents services per unit of computer capital, and $\delta_{C \tau}$ is the approximation error from using investment data in 2000 to measure computer service flows in 1999.

Using these proxies yields the best sample that the data will allow us to create. The sample of plants new in 1997 has 849 observations. We address the concern that the sample is small by constructing a second sample based on a broader alternative definition of new that includes plants between three and eight years old. The broader definition includes plants that first appeared in the 1993 through 1996 ASMs and have positive computer investment. These plants are between three and eight years old in 2000, below the ten-year average age of plants in the 1999 CNUS-2000 ASM linked data set. ${ }^{4}$ The value of the capital approximation errors, $\delta_{T \tau}$ and $\delta_{C \tau}$, will be higher for these plants than for plants that are new in 1997, but including them yields a larger sample of 1,755 observations.

To test the importance of using the sample of plants for which we have relatively better proxies for total and computer capital stock, we use the linked data to construct a data set containing plants of all ages. Our sample of plants of all ages that report positive computer investment has 12,386 observations.

\subsubsection{Estimating the Impact of Computer Networks}

Because computers have been in commercial use in the U.S. for fifty years, they might be viewed as just another capital input. If so, we would expect to find that computer and noncomputer capital yield similar contributions to productivity. Computer networks also have been used for decades. But the networks that came into use more recently are thought to be qualitatively different (e.g., Bresnahan and Greenstein 1997). Brynjolfsson and Hitt (2000) argue that the effects of organizational changes caused by the newer computer networks may rival the effects of changes in the production process. Viewed this way, computer networks are a productivity-enhancing-general-purpose technology (Bresnahan and Trajtenberg 1995). The question for productivity and other measures of economic performance may no longer be whether computers matter, but whether it matters how computers are used.

Despite the importance of understanding whether computer networks matter for productivity, information on networks is scarce. The computer network information collected in the 1999 CNUS is the first such collection for a large and representative national sample of plants in U.S. manufacturing. The CNUS asked about the presence of several kinds of networks, including Internet, Intranet, Local Area Networks (LAN), Electronic Data Interchange (EDI), Extranet, and "other." We create a dummy vari- 
able for the presence of computer networks that takes on a value of one if the plant reports having any of these kinds of computer network and zero otherwise.

The 1999 CNUS network data, together with the computer investment information collected in the 2000 ASM, allow us for the first time to specify an empirical model of labor productivity with separate measures of the presence of computers (computer investment) and how computers are used (computer networks). Using only the information on how businesses use computers (the presence of computer networks), as in our previous research, may overstate the importance of those uses because it is picking up the importance of having computers.

\subsection{Empirical Implementation}

We focus on estimating whether labor productivity is related both to computer networks and computer inputs by estimating the following Cobb-Douglas production function:

$$
\begin{aligned}
\log \left(\frac{Q}{L}\right)= & \beta_{0}+\beta_{1} \mathrm{CNET}+\alpha_{1 c} \log \left(\frac{K_{c}}{L}\right)+\alpha_{1 n c} \log \left(\frac{K_{n c}}{L}\right) \\
& +\alpha_{2} \log \left(\frac{M}{L}\right)+\alpha_{3} \log (\mathrm{MIX})+\alpha_{4} \text { MULTI } \\
& +\sum \gamma_{j} \mathrm{SIZE}_{j}+\sum \lambda_{i} \mathrm{IND}_{i}+\varepsilon
\end{aligned}
$$

where $Q, K_{c}, K_{n c}, L$, and $M$ represent output, computer capital input, noncomputer capital input, labor, and materials. CNET denotes computer networks, and $\beta_{0}+\beta_{1}$ CNET $=A$, the technological change term, that is, the Solow residual or total factor productivity (TFP). SIZE denotes the size class of the plant. MIX denotes the mix of production and nonproduction workers, and MULTI represents plants that belong to a multiunit firm. IND denotes three-digit NAICS industries. $K_{n c} / L$, noncomputer capital input in 1999 , is proxied by $K / L 97$, the book value of total capital in 1997, divided by 1997 employment. $K_{c} / L$ computer capital input in 1999, is proxied by $K_{C 2000} / L$, computer investment in 2000 , divided by employment in 1999.

Our model distinguishes between the productive effect of computer input in the plant and a technological shift resulting from using computer networks. Equation (4) directly relates computer networks and computer capital to $(\log )$ labor productivity. In this formulation, $\beta_{1}$, is one of our two parameters of interest. It can be interpreted as measuring the relationship between computer networks and labor productivity, controlling for the in- 
tensities of computer and noncomputer capital $\left(K_{c} / L\right.$ and $\left.K_{n c} / L\right)$, materials intensity $(M / L)$, and other plant characteristics.

The second parameter of interest is $\alpha_{1 c}$, the coefficient on the intensity of computer capital. This coefficient can be interpreted as a return to the flow of services from the stock of computer capital.

Labor productivity is defined as output per worker $(Q / L)$. We use total value of shipments (TVS) as a measure of $Q$. Our measure of labor, $L$, is the total number of employees in the plant. Our model differs from those in most previous related plant-level studies in specifying a four-factor production function in which output is defined as gross output (rather than value added), and materials are incorporated as a separate input in production.

We described earlier how we use the CNUS, ASM, and CM to specify computer networks, computer inputs, and total capital inputs. We use the same empirical specifications of materials, skill mix, size, multiunit plant status, and industry as Atrostic and Nguyen (2005). The CNUS data are part of a Census Bureau measurement initiative to fill some of the data gaps on the growing use of electronic devices and networks in the economy (Mesenbourg 2001). The appendix contains more information on the 1999 CNUS, 2000 ASM, and the 1992 and 1997 CM.

\subsection{Empirical Findings}

We estimate relationships among computer networks, computer input, and labor productivity using three alternative specifications. The preferred specification includes both computer networks and computer inputs. A specification that parallels our prior research includes computer networks but not computer inputs. The third specification parallels specifications in the literature that include computer inputs but not computer networks.

The three specifications are estimated first for the cohort of 849 plants that newly opened their operations in 1997 and had positive computer investment in 2000. We report these results in table 13.1. To assess whether it matters that we restrict our sample to plants that were new in 1997, we estimate the same three specifications using two other samples. Estimates from the sample of 1,755 relatively new plants that opened between 1993 and 1997 and have positive computer investment in 2000 are reported in table 13.2. ${ }^{5}$ Estimates from the sample of 12,836 plants of all ages that have positive computer investment in 2000 are also reported in table 13.2. This data set allows us to assess the empirical importance of using proxies for

5. We also create four subsamples of plants that are new in each year between 1997 and 1992. The results are similar to the results for plants new in 1997 and all plants that are new between 1992 and 1997, so we do not report them separately. 
Table 13.1

Labor productivity OLS regression results: Plants new in 1997

\begin{tabular}{|c|c|c|c|c|}
\hline \multirow[b]{3}{*}{ Independent variable } & \multicolumn{4}{|c|}{ Plants with positive computer investment in 2000} \\
\hline & \multicolumn{3}{|c|}{ New in 1997} & \multirow{2}{*}{$\begin{array}{c}\text { All plants } \\
(4)\end{array}$} \\
\hline & (1) & (2) & (3) & \\
\hline \multirow[t]{2}{*}{ Intercept } & $3.769 * * *$ & $3.051 * * *$ & $3.266^{* * *}$ & $2.949 * * *$ \\
\hline & $(32.63)$ & $(32.36)$ & $(38.00)$ & $(106.03)$ \\
\hline \multirow[t]{2}{*}{ CNET } & $.117^{* *}$ & $.136^{* * *}$ & & .004 \\
\hline & $(2.12)$ & $(2.44)$ & & $(0.25)$ \\
\hline \multirow[t]{2}{*}{$\log \left(K_{n c} / L\right)$} & $.086^{* * *}$ & $.093 * * *$ & $.088 * * *$ & $.098 * * *$ \\
\hline & $(6.02)$ & $(6.42)$ & $(6.13)$ & $(26.92)$ \\
\hline \multirow[t]{2}{*}{$\log \left(K_{c} / L\right)$} & $.050^{* * *}$ & & $.052^{* * *}$ & $.0478 * * *$ \\
\hline & $(4.36)$ & & $(4.53)$ & (16.03) \\
\hline \multirow[t]{2}{*}{$\log (M / L)$} & $.409 * * *$ & $.422 * * *$ & $.409 * * *$ & $.478^{* * *}$ \\
\hline & $(28.00)$ & $(29.15)$ & $(27.96)$ & $(121.97)$ \\
\hline \multirow[t]{2}{*}{ MIX } & $.040^{*}$ & $.061 * * *$ & $.044^{*}$ & $0.04 * * *$ \\
\hline & $(1.69)$ & $(2.64)$ & $(1.85)$ & $(7.08)$ \\
\hline \multirow[t]{2}{*}{ MULTI } & $.161^{* * *}$ & $.155^{* * *}$ & $.167 * * *$ & $.102 * * *$ \\
\hline & $(4.81)$ & $(4.59)$ & $(5.00)$ & $(11.45)$ \\
\hline Plant size & Yes & Yes & Yes & Yes \\
\hline Industry (3-digit NAICS) & Yes & Yes & Yes & Yes \\
\hline$R^{2}$ & .655 & .647 & .653 & .740 \\
\hline No. of plants & 849 & 849 & 849 & 12,386 \\
\hline
\end{tabular}

Notes: Dependent variable $=$ labor productivity. $T$-statistics in parentheses. Notation in the table is the same as in the estimating equation (4). $K_{n c} / L$, noncomputer capital input in 1999, is proxied by $K / L 97$, the book value of total capital in 1997 , divided by 1997 employment. $K_{c} / L$, computer capital input in 1999 , is proxied by $K_{c 2000} / L$, computer investment in 2000 divided by employment in 1999. All other variables are measured in 1999.

***Significant at the 1 percent level.

**Significant at the 5 percent level.

*Significant at the 10 percent level.

capital services when they are unlikely to be good measures. Because information on computer networks was collected only in 1999, our analyses are all cross-sectional.

It matters empirically whether data are available to proxy for both computer networks and computer inputs. Each coefficient is higher in the specification that excludes the other measure, suggesting that when each is used alone, it picks up part of the impact of the other. ${ }^{6}$ Computer input and computer networks both have positive and significant relationships to la-

6. We report only OLS estimates. Because we use new, or relatively new, plants, we have no good instruments. The two-stage estimates reported in our prior research did not have the expected result of reducing the estimated effect of computer networks. When we estimate OLS specifications on the same sample used in the two-stage estimates, coefficients of variables other than networks and computer investment are stable. 
Table 13.2

Labor productivity OLS regression results: Plants new between 1992 and 1997

\begin{tabular}{|c|c|c|c|c|}
\hline \multirow[b]{3}{*}{ Independent variable } & \multicolumn{4}{|c|}{ Plants with positive computer investment in 2000} \\
\hline & \multicolumn{3}{|c|}{ New between 1992 and 1997} & \multirow{2}{*}{$\begin{array}{c}\text { All plants } \\
\text { (4) }\end{array}$} \\
\hline & (1) & $(2)$ & (3) & \\
\hline \multirow[t]{2}{*}{ Intercept } & $3.009 * * *$ & $2.916 * * *$ & $3.117 * * *$ & $2.949 * * *$ \\
\hline & $(39.78)$ & $(39.26)$ & $(47.90)$ & (106.03) \\
\hline \multirow[t]{2}{*}{ CNET } & $.126 * * *$ & $.1510 * * *$ & & .004 \\
\hline & $(2.78)$ & $(3.31)$ & & $(0.25)$ \\
\hline \multirow[t]{2}{*}{$\log \left(K_{n c} / L\right)$} & $.084 * * *$ & $.088 * * *$ & $.085^{* * *}$ & $.098 * * *$ \\
\hline & $(8.91)$ & $(9.28)$ & $(9.01)$ & $(26.92)$ \\
\hline \multirow[t]{2}{*}{$\log \left(K_{c} / L\right)$} & $.046^{* * *}$ & & $.049 * * *$ & $.0478 * * *$ \\
\hline & $(5.42)$ & & $(5.71)$ & $(16.03)$ \\
\hline \multirow[t]{2}{*}{$\log (M / L)$} & $.456 * * *$ & $.466 * * *$ & $.457 * * *$ & $.478^{* * *}$ \\
\hline & $(43.38)$ & $(44.54)$ & $(43.34)$ & $(121.97)$ \\
\hline \multirow[t]{2}{*}{ MIX } & $.036^{* *}$ & $.057 * * *$ & $.038 * *$ & $0.04 * * *$ \\
\hline & $(2.13)$ & $(3.51)$ & $(2.25)$ & $(7.08)$ \\
\hline \multirow[t]{2}{*}{ MULTI } & $.143^{* * *}$ & $.137 * * *$ & $.149 * * *$ & $.102 * * *$ \\
\hline & $(5.71)$ & $(5.43)$ & $(5.98)$ & $(11.45)$ \\
\hline Plant size & Yes & Yes & Yes & Yes \\
\hline Industry (3-digit NAICS) & Yes & Yes & Yes & Yes \\
\hline$R^{2}$ & .678 & .672 & .665 & .740 \\
\hline No. of plants & 1,755 & 1,755 & 1,755 & 12,386 \\
\hline
\end{tabular}

Notes: See notes to table 13.1.

*** Significant at the 1 percent level.

** Significant at the 5 percent level.

bor productivity in estimates from our preferred specification, as reported in column (1) of table 13.1. The coefficient on computer networks is 0.117 , controlling for computer and other inputs and plant characteristics. ${ }^{7}$ Noncomputer inputs $\left(K_{n c} / L\right)$ and computer inputs $\left(K_{c} / L\right)$ have separate and significant relationships to productivity, with coefficients of 0.085 and $0.050 .{ }^{8}$ Computer networks are significant when they enter the estimation alone, and the coefficient of 0.136 , reported in column (2), is higher than when computer input is included. When computer networks are excluded,

7. The exponential of the coefficient 0.117 is 1.124 , or a differential of 12.4 percent. However, because the differences between the exponential and the coefficient are not large, we discuss the coefficient rather than the exponential in the text.

8. The cost shares of $K_{n c}$ and $K_{c}$ are 0.28 and 0.005 , while the ratio $K_{c} / K_{n c}$ is 0.09 . Given the low cost share ( 0.5 percent) of computer capital, its coefficient of 0.050 indicates that computer capital input is a highly productive input relative to noncomputer input. Indeed, while the cost share of noncomputer input is 27.7 percent, it contributes only 8.6 percent to total output. In contrast, the cost share of computer input is only 0.5 percent, but it contributes 5 percent to total output. 
computer intensity is significant, with the slightly higher coefficient of 0.052 as reported in column ( 3 ) of table 13.1. ${ }^{9}$

The coefficient of one other variable, MIX, the ratio of nonproduction to production workers, changes appreciably across these specifications. In our preferred specification that includes both computer input and networks (column [1] of table 13.1), the coefficient of MIX is 0.040, but is not significant. An estimate similar in size, 0.044 , and in lack of significance, comes from the specification that includes only computer input (column [3]). By comparison, in the specification that only includes computer networks, the coefficient of MIX increases to 0.061 , suggesting that computer inputs may be positively related to the worker mix ratio (column [3]). Other researchers find similar relationships between worker mix and computer investment (e.g., Dunne et al. 2000; Haltiwanger, Jarmin, and Schank 2003). Coefficients of most other inputs, plant characteristics, and $R^{2}$ change little across the three specifications reported in table 13.1, suggesting that the computer network and computer input measures are independent of other inputs or plant characteristics.

We assess how sensitive these estimates are to the assumption that our proxies for capital and computer service flows are best for new plants by estimating the same three specifications for the largest sample of 1,755 plants that are new between 1992 and 1997. Estimates based on this broader definition of "new" plants yield similar findings. Computer input and computer networks both have positive and significant relationships to labor productivity, as reported in column (1) of table 13.2. The computer network coefficient of 0.126 is significant for relatively new plants with computers, controlling for computer and other inputs and plant characteristics. Computer input has a separate and significant effect, with a coefficient of computer intensity $\left(K_{c} / L\right)$ of 0.046 . When computer networks are excluded, computer intensity remains significant, with a slightly higher coefficient of 0.049 , as reported in column (2) of table 13.2. When computer inputs are excluded, computer networks remain significant, with a higher coefficient of 0.1510 .

Having good proxies for all forms of capital services is empirically important. Coefficients of both computer networks and computer input are significant in all the estimates based on new plants, as reported in tables 13.1 and 13.2. A very different picture emerges from estimates based on plants of all ages. In these estimates, computer networks and computer inputs do not each have empirically separate relationships with labor productivity. The network coefficient of 0.004 , reported in column (4) of table 13.2 , is not statistically significant. Computer input, however, is positively and significantly related to productivity, with a coefficient of 0.0478 . Re-

9. While we calculate coefficients for industry dummies $\lambda$ and for size dummies $\gamma$, we do not report them because such coefficients present standard microdata disclosure problems. 
sults based on this sample of plants of all ages suggest that computer networks are not a technology that shifts the production function, distinct from the productive effect of computer inputs. Instead, computer networks appear simply to be a measure of computer inputs. However, it is for this sample that our proxies for total and computer capital inputs are most problematic.

\subsection{Discussion}

Our empirical findings suggest that computer networks may be a new technology that shifts the production function, not just an alternative measure of the presence of computers. The measurement issues we raise about capital inputs have important empirical consequences because those findings hold only when we have good proxies for capital inputs. When we lack good proxies, we would conclude instead that our cross-section estimates of the separate relationships of productivity with computer networks and computer inputs are subject to omitted variable bias and that the new network variable yields no additional information about the relationship between computer use and productivity in U.S. manufacturing.

We assess these findings by comparing them with results we obtained in our previous study using these data, when only information on computer networks was available, and with results of other researchers. The final portion of this section discusses how remaining data gaps may affect our estimates and what our findings imply for priorities in filling them.

\subsubsection{Comparison with Prior Research Using These Data}

While we do not deal with causality issues, our findings are consistent with our previous research using these data, which showed a significant and positive relationship between computer networks on labor productivity in both ordinary least squares (OLS) and two-stage regressions (Atrostic and Nguyen 2005). Note that our previous and new estimates are not directly comparable because the samples differ in two ways. The sample we use in this paper is for plants that are new in 1997 and have positive computer investment. Our previous research includes plants of all ages, regardless of whether they had computer investment, because data on computer investment in 2000 were not available. ${ }^{10}$ In addition, the previous research includes computer networks but not computer inputs. With those differences in mind, we compare the specifications that are most similar in the new and previous research.

10. We also perform parallel sensitivity assessments between the 12,836-observation data set of plants of all ages that we use in this paper and the 10,496-observation 1999 CNUS-only data used in our previous research (Atrostic and Nguyen 2005). Because the same specification estimated on these two data sets yield similar results to those reported here, we do not discuss them separately. 
The appropriate comparison from our previous research is with computer network coefficients from OLS regressions on the 10,496 observations that we also used in the two-stage estimates. Those OLS estimates, repeated here in column (2) of table 13.3, show that labor productivity is 3.9 percent higher in plants with networks. ${ }^{11}$

For plants new in 1997, the estimated computer network impact is 14.6 percent (the exponential of the coefficient 0.136 in column [2] in table 13.1). This is nearly four times the 3.9 percent impact of networks for plants of all ages. The higher coefficient for new plants might mean that newer plants open with the newest embodied technology. ${ }^{12}$ We note that new plants in our data have lower average productivity, regardless of whether they have networks. What our research finds is that productivity is higher in newer plants that have computer networks, compared to newer plants without networks.

The coefficient of the MIX term, the ratio of nonproduction to production workers, also is higher for the new plants $(0.061$ versus 0.039$)$. This suggests that newer plants that are more productive have a higher proportion of nonproduction workers. Higher ratios of nonproduction to production workers are frequently taken as proxies for higher levels of skills embodied in the workers. Careful research linking the broad groupings of production and nonproduction workers with reports from the 1990 Decennial Census of actual worker education suggests that there can be such embodiment (Doms, Dunne, and Troske 1997). However, we cannot make such linkages with our data. The broad worker classification in the MIX term makes it difficult to read too much into any estimated difference in this coefficient between groups of plants of different ages.

\subsubsection{Comparisons with the Information Technology Literature}

Our finding of positive and significant relationships between computers and computer networks and productivity is consistent with the recent empirical literature at the plant and firm level. Previous research using com-

11. In contrast to standard findings in estimates from OLS versus two-stage regressions, our previous research shows a positive and significant relationship between computer networks and productivity in both estimates, and the estimate in the two-stage regression, 7.2 percent, exceeds the OLS estimate of 3.8 percent. We obtain the 7.2 percent estimate by evaluating the significant coefficient of the predicted network variable $(0.669)$ at the mean of the network variable.

12. The vintage capital model says that newer plants open with the newest, embodied technology and that plants exit when their productivity becomes too low relative to the new entrants. Consistent with the model are results in the literature suggesting that older plants are more likely to exit, but more productive plants are more likely to continue. However, Baily, Hulten, and Campbell (1992) find little evidence for the vintage capital model in examining transition matrices across years in U.S. manufacturing. They and other researchers find that plants entering an industry have low productivity on average but move within a few years to both the highest and lowest productivity groups. Similarly, Power (1998) finds that productivity increases with plant age, but finds almost no relationship between productivity and the age of investments. 


\begin{tabular}{|c|c|c|c|c|c|c|}
\hline \multirow{5}{*}{$\begin{array}{l}\text { Independent variable } \\
\text { Intercept }\end{array}$} & \multicolumn{6}{|c|}{ All CNUS plants ${ }^{a}$} \\
\hline & \multirow{2}{*}{\multicolumn{3}{|c|}{ OLS estimates }} & \multicolumn{3}{|c|}{ Two-stage estimates } \\
\hline & & & & \multirow{2}{*}{\multicolumn{2}{|c|}{$\begin{array}{l}\text { Standard } \\
\text { (3) }\end{array}$}} & \multirow{2}{*}{$\begin{array}{c}\text { Corrected errors }{ }^{\mathrm{b}} \\
\text { (4) }\end{array}$} \\
\hline & (1) & \multicolumn{2}{|c|}{$(2)^{\mathrm{b}}$} & & & \\
\hline & $2.948 * * *(114.95)$ & $2.92 * * *$ & $(90.85)$ & \multicolumn{2}{|c|}{$2.362 * * * \quad(17.23)$} & \multirow[t]{2}{*}{$2.363 * * * \quad(14.68)$} \\
\hline CNET & $0.037^{* * *} \quad(3.00)$ & $0.038 * * *$ & $(2.76)$ & $\mathrm{c}$ & & \\
\hline $\operatorname{Pr}(\mathrm{CNET})$ & & & & $0.669 * * *$ & $(4.39)$ & $0.669^{* * *} \quad(3.88)$ \\
\hline $\log (K / L)$ & $0.078 * * * \quad(24.19)$ & $0.083 * * *$ & $(22.42)$ & $0.082 * * *$ & $(22.10)$ & $0.082^{* * *} \quad(17.52)$ \\
\hline $\log (M / L)$ & $0.451 * * *(118.96)$ & $0.458 * * *$ & (105.21) & $0.459 * * *$ & (105.39) & $0.459^{* * *} \quad(52.21)$ \\
\hline $\log (L)$ & $-0.005^{*}$ & $-0.004 * *$ & $(-1.25)$ & -0.003 & $(-0.94)$ & $-0.003 \quad(-0.082)$ \\
\hline $\log (\mathrm{RLP} 92)$ & $0.276^{* * *} \quad(32.80)$ & $0.277 * * *$ & $(29.91)$ & $0.289 * * *$ & $(29.86)$ & $0.289 * * * \quad(21.47)$ \\
\hline $\log (\mathrm{MIX})$ & $0.035^{* * *} \quad(7.25)$ & $0.032 * * *$ & $(5.83)$ & $0.034 * * *$ & $(6.27)$ & $0.040 * * * \quad(2.74)$ \\
\hline MULTI & $0.088^{* * *}(10.04)$ & 0.082 & $(8.55)$ & $0.04 * * *$ & $(2.85)$ & $0.0482 * * * \quad(3.63)$ \\
\hline New & $0.203^{* * *} \quad(7.15)$ & & & & & \\
\hline $\begin{array}{l}\text { New } \cdot \text { interactions } \\
\text { with inputs above }\end{array}$ & \multicolumn{3}{|l|}{ 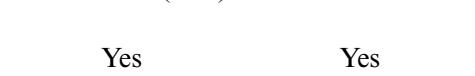 } & \multicolumn{2}{|c|}{ Yes } & Yes \\
\hline \multicolumn{7}{|l|}{ Industry (3-digit } \\
\hline NAICS) & Yes & \multicolumn{2}{|c|}{ Yes } & \multicolumn{2}{|c|}{ Yes } & Yes \\
\hline$R^{2}$ & 0.8133 & \multicolumn{2}{|c|}{0.7811} & \multicolumn{2}{|c|}{0.7724} & 0.7819 \\
\hline No. of plants & 29,840 & \multicolumn{2}{|c|}{10,496} & \multicolumn{2}{|c|}{10,496} & 10,496 \\
\hline
\end{tabular}

Notes: Dependent variable $=$ labor productivity. $T$-statistics in parentheses. $L=$ employment at the plant. RLP92 = the plant's labor productivity in 1992 (1997 for plants new in 1997), relative to its 4-digit SIC industry. New indicates a zero-one dummy variable equal to one for plants new since 1997 . K/L, total capital input in 1999 , is proxied by $K / L 97$, the book value of total capital in 1997 . Other variables defined as in tables 13.1 and 13.2.

${ }^{a}$ All coefficients are reported in Atrostic and Nguyen (2005).

${ }^{\mathrm{b}}$ The number of observations in columns (2), (3), and (4) is smaller than that in column (1) for several reasons. Estimating the probit in the first stage of the two-stage estimates reported in columns (3) and (4) required variables from prior periods that are not used in the OLS estimates. One of these variables, computer expenditures, is reported by only about half of all plants. Additionally, many plants are new since the prior period, 1992. The OLS regression reported in column (2) uses the same reduced sample that is used in the two-stage estimates.

'Evaluating the coefficient of the predicted probability at a point consistent with our data yields an estimated network effect of 7.2 percent. This estimated network effect is higher than the OLS estimate of 3.9 percent from the coefficients in column (2).

***Significant at the 1 percent level.

**Significant at the 5 percent level.

*Significant at the 10 percent level.

puter investment data for U.S. manufacturing through 1992 found a positive link between computer investment and plant-level productivity, with much variation among industries (Stolarick 1999a,b). Two recent reviews of plant- or firm-level empirical studies of information technology (including but not limited to computers) and economic performance (Dedrick, Gurbaxani, and Kraemer 2003; Stiroh 2004) conclude that the lit- 
erature shows positive relationships between information technology and productivity.

Dedrick, Gurbaxani, and Kraemer (2003) review over 50 articles published between 1985 and 2002, many of which are firm-level studies with productivity as the performance measure. They conclude that firm-level studies show positive relationships, and that gross returns to information technology (IT) investments exceed returns to other investments. ${ }^{13}$

Stiroh (2004) conducts a meta-analysis of twenty recent empirical studies of the relationship between information technology and the production function. He also estimates a number of specifications used in those studies on a single industry-level database. The meta-analysis of nineteen firmlevel studies that use gross output productivity measures yields a mean elasticity of information technology of 0.042 , with large variability around that coefficient. His estimates using the single industry-level database yield OLS estimates of computer capital elasticity of $0.047 .{ }^{14}$ The coefficient estimate, however, is sensitive to econometric specifications that account, for example, for unobserved heterogeneity.

Stiroh's (2004) meta-analysis and basic OLS regression estimates are close to the coefficient of 0.050 that we report for computer capital elasticity in new plants in our preferred specification in column (1) of table 13.1. His estimates are the same as the coefficient of 0.046 that we report in estimates based on our larger sample of plants that are new between 1993 and 1997.

While we are reassured by this empirical regularity, we do not make overly much of it. The estimates in Stiroh's (2004) analysis may not be adjusted for the high obsolescence rate of computers, the well-known continuing decline in computer prices, or coinvention. Our estimates are for the specific sample for which our data have reasonable proxies, plants that are new in 1997. While we obtain similar results for a larger sample of plants that are new since 1992 ( 0.117 versus 0.126$)$, we note that both these estimates far exceed the coefficient estimates for the full sample of plants that report computer investment (0.004), or the network coefficient for the full sample of plants, omitting computer investment (0.037). It also is subject to other biases whose net effects may be of any sign. There is some downward bias because computer prices continue to fall at a roughly 30 percent annual rate of decline, so the plant's computer investment in 2000 buys much more computer input than the same dollar investment would have

13. They warn against concluding that higher gross returns mean that plants are underinvesting in information technology. Most studies do not adjust for the high obsolescence rate of information technology capital, which lowers net returns. Also, total investment in information technology may be understated because most studies measure only computer hardware, but not related labor or software, or costs of coinvention, such as reengineering business processes to take advantage of the new information technology.

14. Both Dedrick, Gurbaxani, and Kraemer (2003) and Stiroh (2002) attribute the failure of early microdata studies to find a relationship to inadequate data with small sample sizes. 
bought even in 1999. We assume this price decline affects all plants in the CNUS equally. There is an upwards bias in our estimates, as in the estimates in Stiroh (2004), because we do not measure coinvention. Coinvention is estimated to equal roughly the cost of the hardware and peripheral equipment investment over the life of the investment, so omitting it understates computer inputs.

Our findings also are consistent with a relatively new literature in plantor firm-level research conducted in other countries and summarized in Pilat (2004). Many studies cited there find positive relationships between information technology and productivity. Several of those studies also find positive relationships between using computer networks and productivity (e.g., Baldwin and Sabourin (2001) for Canada; Bartelsman, van Leeuwen, and Nieuwenhuijsen (1996) for the Netherlands; and Clayton et al. (2004) for the United Kingdom). Recent research by Motohashi (2003) finds separate positive effects of computer expenditures and computer networks in Japan during the 1990-2001 period, with larger effects in more recent years, but also with much heterogeneity in those effects over time and across industries. Many of these new plant- and firm-level studies conclude that computers are not the only factors contributing to productivity. They find important roles for complementary inputs and investments, such as organizational capital, worker skills, and innovation..$^{15}$

While our coefficient estimates for the computer and total capital variables are consistent with the literature, we note again that our computer and total capital variables are proxies for the desired capital input measures. It is difficult to interpret coefficients of these proxy variables as the theoretically specified marginal products of computer and total capital. Stiroh (2004) concludes that information technology matters, but "[r]easonable differences in econometric techniques yield a wide range of estimates," (23) and "one must be careful about putting too much weight on any given estimate" (24). We agree.

\subsubsection{Parallels to the Growth Accounting Literature}

We can use our econometric estimates to quantify the contributions of inputs and computer networks to the change in productivity (both labor and total factor productivity). To get a sense of the contribution of networks, we perform a "productivity change accounting" or decomposition exercise at the microlevel similar to the growth accounting exercise that is often performed to explain the growth of output of goods and services. The conventional "growth accounting" equation can be written as ${ }^{16}$

15. Recent research for the United States using detailed firm-level investment in computers, communications equipment, software, and other capital goods finds that many components of investment, including information technology investments, are related to productivity (Wilson 2004).

16. See, for example, Schreyer (1999) and Jorgenson and Stiroh (2000). 


$$
\Delta Q=\sum \alpha_{i} \Delta X_{i}+\Delta A
$$

where $\Delta Q=\ln \left(Q_{t} / Q_{t-1}\right)=$ output growth,

$\alpha_{i}=$ the output elasticity of input $i$,

$\Delta X_{i}=\ln \left(X_{i t} / X_{i t-1}\right)=$ the growth of input $i$, and

$\Delta A=\ln \left(A_{t} / A_{t-1}\right)=$ total factor productivity (TFP) change.

Within the context of our cross-section productivity model, the preceding equation can be rewritten in terms of moving from the 25 th to the 75 th percentile of the distributions of outputs and inputs: ${ }^{17}$

$$
\Delta q=\sum \alpha_{i} \Delta x_{i}+\Delta A
$$

where $\Delta q=\ln \left[(Q / L)_{75} /\left(Q / L_{25}\right)\right]=$ the rate of change of output between the 25th and 75th percentiles,

$\alpha_{i}=$ the output elasticity of input $i$,

$\Delta x_{i}=\ln \left[(X / L)_{i 75} /(X / L)_{i 25}\right]=$ the rate of change of input $i$ between the 25th and 75th percentiles; and

$\Delta A=\ln \left[A_{75}(C N E T) / A_{25}(C N E T)\right]=$ the rate of change of TFP, which in this model is a function of computer networks, or CNET. ${ }^{18}$

The results of this accounting exercise for U.S. manufacturing plants' labor productivity are in table 13.4. We perform the exercise for the plants with positive computer investment in 2000 . We look separately at plants that are new in 1997, plants that are new between 1992 and 1997, and all plants with positive computer investment. For each group of plants, we estimate the percentage increases in labor productivity due to moving from the 25th to the 75th percentile of the three input variables of interest, log of computer intensity $\left(K_{c} / L\right), \log$ of noncomputer capital intensity $\left(K_{n c} / L\right)$, and $\log$ of materials intensity $(M / L)$. The Solow residual (TFP), $\Delta A(\mathrm{CNET})$, is decomposed into the contribution of the presence of a computer network (CNET) and other factors. The decomposition results in table 13.4 are based on the estimated coefficients in our preferred specifications of equation (4).

Consider the first entry in column (2) of the first panel for new plants, 12.20 percent. This entry suggests that differences in the intensity of noncomputer capital $\left(K_{n c} / L\right)$ contribute about 12 percent to the total change

17. Criscuolo, Haskell, and Slaughter (2005) perform a similar exercise for a single period of cross-section microdata, but in a different context. They focus on accounting for how much differences in the sources of innovation that they measure explain differences in firm output.

18. We actually estimate the effect of differences in computer networks at the 10 th and 75 th percentiles because networks are present in roughly 90 percent of the plants in our sample. To simplify notation and presentation, we use the "25th to 75 th percentile" description for all variables in this section of the paper. 


\begin{tabular}{|c|c|c|}
\hline Variables (elasticities) & $\begin{array}{l}\text { Moving from } \\
25 \text { th to } 75 \text { th } \\
\text { percentile } \\
\text { (1) }\end{array}$ & $\begin{array}{c}\text { Contribution } \\
\text { to change in } \\
\text { productivity }(\%) \\
(2)\end{array}$ \\
\hline \multicolumn{3}{|c|}{ Plants new in $1997(N=849)^{\mathrm{d}}$} \\
\hline$\Delta \mathrm{q}$ & 0.9098 & 100.00 \\
\hline$\Delta K_{n c} / L(0.086)$ & {$[0.086(1.29)] / 0.9098=0.1220$} & 12.20 \\
\hline$\Delta K_{c} / L(0.050)$ & {$[0.050(1.95)] / 0.9098=0.1072$} & 10.72 \\
\hline$\Delta M / L(0.409)$ & {$[0.409(1.31)] / 0.9098=0.5910$} & 59.10 \\
\hline$\Delta$ Total input & & 82.02 \\
\hline Residual $^{\mathrm{c}}$ & & 17.98 \\
\hline$\Delta \mathrm{CNET} / \Delta \mathrm{q}$ & $.117 / .9098$ & 12.86 \\
\hline$(\Delta \mathrm{CNET} / \Delta \mathrm{q}) /$ residual & $12.86 / 17.98=0.7152$ & 71.52 \\
\hline \multicolumn{3}{|c|}{ Plants new between 1992 and $1997(N=1,775)^{\mathrm{e}}$} \\
\hline$\Delta \mathrm{q}$ & 0.9859 & 100.00 \\
\hline$\Delta K_{n c} / L(0.084)$ & {$[0.084(1.41)] / 0.9859=0.1198$} & 11.98 \\
\hline$\Delta K_{c} / L(0.046)$ & {$[0.046(2.01)] / 0.9859=0.0995$} & 9.95 \\
\hline$\Delta M / L(0.456)$ & {$[0.046(1.36)] / 0.9859=0.6282$} & 62.82 \\
\hline$\Delta$ Total input & & 84.75 \\
\hline Residual $^{\mathrm{c}}$ & & 15.25 \\
\hline$\Delta \mathrm{CNET} / \Delta \mathrm{q}$ & $.126 / .9859=.1278$ & 12.78 \\
\hline$(\Delta \mathrm{CNET} / \Delta \mathrm{q}) /$ residual & $12.78 / 15.25=0.8380$ & 83.80 \\
\hline \multicolumn{3}{|c|}{ Plants of all ages with positive capital investment in $2000(N=12,386)^{\mathrm{f}}$} \\
\hline$\Delta \mathrm{q}$ & 0.9181 & 100.00 \\
\hline$\Delta K_{n c} / L(0.098)$ & {$[0.098(1.24)] / 0.9181=0.1323$} & 13.23 \\
\hline$\Delta K_{c} / L(0.0478)$ & {$[0.048(1.94)] / 0.9181=0.1073$} & 10.73 \\
\hline$\Delta M / L(0.478)$ & {$[0.478(1.20)] / 0.9181=0.6248$} & 62.48 \\
\hline$\Delta$ Total input & & 86.44 \\
\hline Residual $^{\mathrm{c}}$ & & 13.56 \\
\hline$\Delta \mathrm{CNET} / \Delta \mathrm{q}$ & $.004 / .9181=0.0043$ & 0.43 \\
\hline$(\Delta \mathrm{CNET} / \Delta \mathrm{q}) /$ residual & $0.43 / 13.56=0.0317$ & 3.17 \\
\hline
\end{tabular}

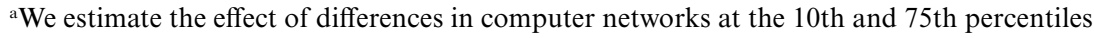
because networks are present in roughly 90 percent of the plants in our sample. To simplify notation and presentation, we use the " 25 th to 75 th percentile" description for all variables in this section of the paper.

${ }^{\text {b}}$ The estimated increase in labor productivity in column (2) are calculated by comparing plants at different points in the distribution of the variables. Specifically, the second number in column (2) minus the contribution of $\Delta K_{n c} / L$ to $\Delta q$, is calculated as: [0.086(1.29)]/.9098 = $0.1220(=12.20 \%)$.

${ }^{\mathrm{c}}$ The residual in this table includes the share explained by the plant characteristics, such as industry, included in our empirical specification and the share unexplained by any variables included in the regression.

${ }^{\mathrm{d}}$ The estimated elasticities are taken from column (1), table 13.1.

${ }^{\mathrm{e}}$ The estimated elasticities are taken from column (1), table 13.2.

${ }^{\mathrm{f}}$ The estimated elasticities are taken from column (4), table 13.2. 
in plant-level labor productivity. Differences in the intensity of computer capital, $K_{c} / L$, account for about 11 percent of the productivity differential, and differences in materials intensity, $M / L$, account for about 59 percent. These three inputs together account for 82 percent of the change in labor productivity as the plant moves from the 25 th to the 75 th percentile of the distributions of each input. The residual (TFP) contributes about 18 percent of the change in labor productivity.

We decompose the residual into the share explained by the presence of computer networks and the share that remains unexplained. ${ }^{19}$ The table shows that the presence of computer networks explains 71.5 percent of the residual, or about 13 percent of the change in the plant's labor productivity. Computer networks and computer and noncomputer capital have comparable contributions to labor productivity.

The second panel of table 13.4 repeats this decomposition exercise for plants that were new between 1992 and 1997. The productivity contributions of inputs and computer networks for these plants, shown in column (2), are similar to those for new plants: the presence of a computer network has an impact analogous to an increase in the intensity of either noncomputer or computer capital.

In the third panel of table 13.4, we apply this decomposition to all plants that had positive computer investment in 2000, regardless of plant age. The contribution of either kind of capital intensity ranges from of 10 to 14 percent, similar to the increases for the two groups of younger plants. However, unlike the results for new plants, the decomposition for plants of all ages shows no role for computer networks. This lack of productivity impact is analogous to the lack of statistical significance we found for computer networks in the OLS regression for plants of all ages in column (4) of table 13.2. The lack of significance may reflect an inability of older plants to make effective use of new technologies. However, as we argue in the preceding, it also reflects serious measurement errors in both computer and noncomputer capital.

This decomposition exercise gives a sense of the relative importance of standard input variables and the computer network variable in our data. Comparisons with other studies are problematic. Most studies in the standard growth accounting literature use different models, different data, and a different unit of analysis. Standard production function models underlay both our research and growth accounting, but our empirical model focuses

19. Because we estimate our model using detailed microdata, the residual has three components: (a) the share that is explained by our variable of interest, the computer network term CNET; (b) the share explained by the other plant characteristics, such as industry, included in our empirical specification; and (c) the share unexplained by any variables included in the regression. The "unexplained" residual we report in table 13.4 and discuss in this section includes both the second and third of these components. Because our interest is in examining the share of the residual explained by CNET, we do not decompose further the 15 to 20 percent of the residual that is not explained by CNET. 
on labor productivity, while growth accounting often looks at output growth. Our data are cross-section data at the plant level and limited to manufacturing, while the growth accounting literature is based on time series data aggregated to the industry or economy level and often includes most or all sectors of the economy. ${ }^{20}$

With these important differences in mind, some broad comparisons show that our empirical results are consistent with those in the growth accounting literature. Jorgenson and Stiroh (2000) calculate the contributions of four inputs - capital, labor, energy, and materials - to U.S. economic growth by industry for the period 1958 through 1996. To illustrate, we use the contributions they report to calculate the share of output growth due to each input, and the unexplained share, for three of these manufacturing industries. The industries we choose - paper products, primary metals, and industrial machinery and equipment-differ in input mix and economic performance. The share of output growth that is due to capital ranges from 11 percent (Primary Metals and Industrial Machinery and Equipment) to 17 percent (for Paper Products). Our estimates of the contribution of noncomputer capital range from 12 to 13 percent, well within the same ballpark. The share of growth unexplained by these inputs in Jorgenson and Stiroh ranges from a low of 14 percent in Paper Products to a high of 31 percent for Industrial Machinery and Equipment. Our estimates of the residual's share of the change in labor productivity run from 14 to 18 percent, at the low end of their estimates.

A second comparison is with growth accounting exercises by Oliner and Sichel (2000) and Jorgenson and Stiroh (2000) for the entire economy that include IT as a separate element of capital services. These studies use different source data and cover slightly different time periods. We choose the results for the period nearest our data, 1996-1999 for Oliner and Sichel and 1995-1998 for Jorgenson and Stiroh, as reported in tables 1A and 1B of Bosworth and Triplett (2001). We again calculate the share of each input to the reported growth of output, and the share of growth that is unexplained. The IT share of output growth is 23 percent in Oliner and Sichel and 20 percent for Jorgenson and Stiroh, with the residual accounting for 24 and 21 percent of output growth. The shares of IT are roughly twice as high in both of these studies as in ours, but the residual shares are similar.

\subsubsection{Important Data Gaps and Implications for Data Collections}

The new network data in the 1999 CNUS and the computer investment data in the 2000 ASM are critical to understanding how IT affects plantlevel productivity. Assessments of the data needed to understand the

20. A series of plant-level studies, beginning with Baily, Hulten, and Campbell (1992) and including studies cited in Schreyer (1999), perform growth decompositions using panel data but do not include computers as a separate input. 
emerging electronic economy, for example, Atrostic, Gates, and Jarmin (2000), and Haltiwanger and Jarmin (2000), identified the lack of information on these variables as critical gaps. Recent data initiatives attempted to fill these gaps by collecting this information for large and nationally representative samples (Mesenbourg 2001).

Early microdata studies lacked large representative national samples collected by official statistical organizations. For example, Dedrick, Gurbaxani, and Kraemer (2003) report that Barua, Kriebel, and Mukhopadhyay (1995) draws on sixty business units in twenty U.S. companies. Similarly, Brynjolfsson and Hitt (2000, 2003) and Brynjolfsson et al. (2002) analyze between 500 and 600 firms for which they combine information from a private database on the firms' computer capital stock with public information on other inputs and financial variables from Compustat.

Larger samples of roughly 38,000 plants became available in the 1988 and 1993 Surveys of Manufacturing Technology (SMT), but were limited to five two-digit Standard Industrial Classification (SIC) industries. Also, while the SMT collected data on the use of a number of technologies, Doms, Dunne, and Troske (1997) stress that they are process and control technologies, and not measures based directly on the use of computers. The computer network and investment data that we use in this paper, by contrast, were asked of the roughly 50,000 plants in the ASM sample, and these plants are distributed among all the NAICS manufacturing industries.

The gap in information on computer capital is being addressed in several ways. Plant-level data on computer investment is collected in the 2001, 2002, 2003, and 2004 ASM. The 2002 Economic Census collected data on both the book values of assets and capital expenditures, with separate information on expenditures on computer equipment and peripherals. In addition, beginning in 2003, the Annual Capital Expenditures Survey (ACES) collects information on both capitalized and expensed expenditures on information and communications technology structures and equipment, including computer software. Because ACES data are collected at the company level, neither totals nor separate detail for expenditures on these information technology expenditures will be available at the plant level.

However, our empirical findings suggest that the key new variable in our analysis is computer networks. Computer network information was only collected in 1999. Lacking network information for multiple periods means that we cannot conduct logical next steps in empirical work. Panel data techniques address many standard plant-level measurement issues, including unobserved heterogeneity beyond those input and plant characteristics we control for, such as managerial ability. Nor can we investigate how the presence of computers and computer networks affect the dynamics of plant performance.

The 1999 CNUS shows that filling this gap is not difficult. The network measure we use was constructed from a few pieces of information (U.S. 
Census Bureau 2002). Our empirical findings show that this measure alone conveys important information about firm heterogeneity in the uses of computers and, in particular, on the newest uses. Room for its components should be eked out of survey instruments and respondent burden calculations.

\subsection{Conclusions}

We find that it is important empirically to have a separate measure of how businesses use computers. Production functions estimates using variables derived from new data on computer networks and computer investment show that both variables have positive and significant relationships with plant-level labor productivity. This finding suggests that computer networks are a new technology that shifts the production function, distinct from the productive effect of computer inputs in the production process. We also show that it is important empirically to have good proxies for computer networks and computer and total capital inputs. When we lack good proxies, computer networks appear to be just an alternate measure of computers.

New data raise the level in the statistical glass but also raise our expectations for the questions we can answer, without enabling us to address all them (Griliches 1994). These new data allow us to estimate single-period models, but not panel or other multiperiod models, and we lack any measures of other variables, such as worker or managerial quality, that have been found important in other empirical studies. The statistical glass nevertheless is filled higher for U.S. manufacturing than for other sectors. Data on variables critical to this analysis, such as computer networks, computer input, book value of capital, and other inputs, are rare in official U.S. data collections for sectors outside of manufacturing.

\section{Appendix}

\section{Data and Empirical Specification of Variables}

\section{Data}

The 1999 Annual Survey of Manufactures Computer Network Use Supplement was mailed to the plants in the ASM sample in mid-2000. The supplement asked about the presence of computer networks and the kind of network (EDI, Internet, both). It also collected information about manufacturers' e-commerce activities and use of e-business processes. The questionnaire asked if the plant allowed online ordering and the percentage of total shipments that were ordered online. Information on online purchases 
was also asked. In addition, information was collected about the plant's current and planned use of about twenty-five business processes conducted over computer network (such as procurement, payroll, inventory, etc."e-business processes") and the extent to which the plant shared information online with vendors, customers, and other plants within the company.

The Annual Survey of Manufactures (ASM) is designed to produce estimates for the manufacturing sector of the economy. The manufacturing universe consists of approximately 365,000 plants. Data are collected annually from a probability sample of approximately 50,000 of the 200,000 manufacturing plants with five or more employees. Data for the remaining 165,000 plants with fewer than five employees are imputed using information obtained from administrative sources. Approximately 83 percent of the plants responded to this supplement. All CNUS data are on the North American Industry Classification System (NAICS) basis. Because the data are only from respondents to the CNUS and are not weighted (see the discussion in http://www.census.gov/estats), our results may apply only to responding plants. We note, however, that the plants responding to the CNUS account for a substantial share of the U.S. manufacturing employment and output (about 50 to 60 percent) represented in the ASM.

\section{Variables}

- Capital $\left(K_{T}\right)$ : Data on capital services are the appropriate measure for production function estimation and productivity analysis. Because such data are not available at the micro level, we use book values of gross capital stocks (including buildings and machinery assets) collected in the $1997 \mathrm{CM}$ as a proxy for $K$. We use 1997 data on capital intensity $(K / L)$ because data on total capital stock are collected in the 1997 Economic Census but not in the ASM (see table 13A.1). Although we recognize that these data have limitations as measures of capital services, it is widely recognized that it is difficult to handle these problems in cross-sectional analysis. We therefore follow many previous studies (e.g., McGuckin, Streitwieser, and Doms 1998; Greenan, Mairesse, and Topiol-Bensaid 2001) and use book values of capital as a proxy for capital input, $K$. This implies that services are proportional to the book value of capital. This assumption is made more reasonable by the controls for plant characteristics in our regressions.

- Computer Investment $\left(I_{C}\right)$ : This is computer investment as reported in the 2000 ASM.

- Materials $(M)$ : These are the sum of values of materials and parts, values of energy consumed (including electricity and fuels), and values of contract work.

- Skill Mix (MIX): This variable is defined as the number of nonproduction workers (OW) divided by total employment (TE) in the plant, as reported on the 1999 ASM. Computer networks require highly 
Table 13A.1 Computer and capital input and computer network data in the Annual Survey of Manufactures and the Census of Manufactures, 1987-2002

\begin{tabular}{|c|c|c|c|}
\hline Year & Total capital ${ }^{\mathrm{a}, \mathrm{b}}$ & Computer investment & Computer network \\
\hline \multicolumn{4}{|c|}{ Data available when study was conducted } \\
\hline 1987 & $X$ & $\mathrm{X}$ & \\
\hline \multicolumn{4}{|l|}{1988} \\
\hline \multicolumn{4}{|l|}{1989} \\
\hline \multicolumn{4}{|l|}{1990} \\
\hline 1992 & $\mathrm{X}$ & $\mathrm{X}$ & \\
\hline \multicolumn{4}{|l|}{1993} \\
\hline \multicolumn{4}{|l|}{1994} \\
\hline \multicolumn{4}{|l|}{1995} \\
\hline \multicolumn{4}{|l|}{1996} \\
\hline 1997 & $X$ & & \\
\hline \multicolumn{4}{|l|}{1998} \\
\hline 1999 & & & $\mathrm{X}$ \\
\hline 2000 & & $\mathrm{X}$ & \\
\hline 2001 & & $\mathrm{X}$ & \\
\hline 2002 & $X$ & $X$ & \\
\hline
\end{tabular}

${ }^{a}$ Book value.

${ }^{\mathrm{b}}$ Annual Survey of Manufactures sample of the Census of Manufactures only.

skilled workers to develop and maintain them. Productivity might thus be higher at plants with a higher proportion of skilled labor because these workers are able to develop, use, and maintain advanced technologies, including computer networks. But applications such as expert systems may allow a function to be carried out with employees who have lower skill levels or with fewer employees. ${ }^{21}$

- SIZE: Plant size is specified as a standard series of six dummy vari-

21. Occupational detail would be desirable to test the relationship among productivity, networks, and the presence of such skilled occupations as computer programmers and systems support staff (e.g., Greenan, Mairesse, and Topiol-Bensaid (2001) and Motohashi (2001). However, the ASM only collects information on the total numbers of production and nonproduction workers in the plant, with no further detail by process, function, or worker characteristic. Dunne and Schmitz (1995) found that plants in the 1988 SMT that used advanced technologies had higher ratios of nonproduction to total workers. Doms, Dunne, and Troske (1997) find that plants that adopt new technologies have more skilled workforces both before and after adoption. As with many other plant-level studies, we use this employment ratio to proxy for skill mix in our productivity estimates. Production workers accounted for about onequarter (27 percent) of employment among CNUS respondents in manufacturing. This share is similar to shares reported for the five two-digit U.S. Standard Industrial Classification (SIC) industries in the 1988 and 1993 SMTs (e.g., McGuckin, Streitwieser, and Doms 1998).

However, some production workers are in highly skilled occupations, and some nonproduction workers are in relatively less-skilled jobs such as janitors, and the literature is scarcely unanimous that the nonproduction labor share is a measure of skill (e.g., Dunne, Haltiwanger, and Troske [1997]; Berman, Bound, and Griliches [1994]). We follow Dunne et al. (2000) in both using this measure and being cautious in interpreting it as an indicator of skill. 
ables. About 30 percent of the plants in our core CNUS sample have fewer than 50 employees, 20 percent have between 50 and 99 employees, about 30 percent have between 100 and 250 employees, and the remaining 20 percent are in larger plants.

- Multiunit Firms' Plants (MULTI): Many manufacturing plants are part of multiunit firms, so employment size alone is an inadequate indicator of available resources, managerial expertise, and scale. We construct a dummy variable, MULTI, that takes on the value of one if the plant is part of a multiunit firm, and equals zero otherwise. Nearly two-thirds of the plants in our sample are part of a multiunit firm.

- Industries (IND): All previous studies of plant-level behavior note substantial heterogeneity among plants within detailed manufacturing industries as well as between detailed industries. There are twentyone three-digit NAICS manufacturing industry groups in our sample (NAICS codes 311-316, 321-327 and 331-337). Industry dummies (IND) are included in the basic empirical model specifications to capture industry-specific effects on plant-level labor productivity.

\section{References}

Atrostic, B. K., J. Gates, and R. Jarmin. 2000. Measuring the electronic economy: Current status and next step. Center for Economic Studies Discussion Papers in Economics no. CES 00-10. Washington, DC: U.S. Bureau of the Census, June.

Atrostic, B. K., and S. Nguyen. 2005. IT and productivity n U.S. manufacturing: Do computer networks matter. Economic Inquiry 43 (30): 493-506.

Baily, M. N., C. Hulten, and D. Campbell. 1992. Productivity dynamics in manufacturing plants. Brookings Papers on Economic Activity, Microeconomics: 187267.

Baldwin, J., and D. Sabourin. 2004. Impact of the adoption of advanced information and communication technologies on firm performance in the Canadian manufacturing sector. Analytical Studies Research Paper no. 11F0019MIE20001174. Ottowa, Canada: Statistics Canada.

Bartelsman, E., G. van Leeuwen, and H. R. Nieuwenhuijsen. 1996. Advanced manufacturing technology and firm performance in the Netherlands. Netherlands Official Statistics 11 (autumn): 40-51.

Barua, A., D. J. Kriebel, and T. Mukhopadhyay. 1995. Information technologies and business value: An analytic and empirical investigation. Information Systems Research 6 (1): 3-23.

Becker, R., J. Haltiwanger, R. Jarmin, S. Klimek, and D. Wilson. 2004. Micro and macro data integration: The case of capital. Paper presented at the NBER/ CRIW conference on the Architecture of the National Accounts, Washington, DC.

Berman, E., J. Bound, and Z. Griliches. 1994. Changes in the demand for skilled labor within U.S. manufacturing: Evidence from the Annual Survey of Manufacturers. The Quarterly Journal of Economics 109 (2): 367-97.

Bosworth, B., and J. Triplett. 2001. What's new about the new economy? IT, eco- 
nomic growth and productivity. International Productivity Monitor 2 (spring): $19-30$.

Bresnahan, T., and S. Greenstein. 1997. Technical progress and coinvention in computing and the uses of computers. Brookings Papers on Economic Activity, Macroeconomics: 1-78.

Bresnahan, T., and M. Trajtenberg. 1995. General purpose technologies: Engines of Growth? Journal of Econometrics 65:83-108.

Brynjolfsson, E., and L. M. Hitt. 2000. Beyond computation: Information technology, organizational transformation and business performance. Journal of Economic Perspectives 14 (fall): 23-48.

. 2003. Computing productivity: Firm-level evidence. Review of Economics and Statistics 84 (4): 793-808.

Brynjolfsson, E., L. Hitt, S. Yang, M. N. Baily, and R. Hall. 2002. Intangible assets: Computers and organizational capital/comments and discussion. Brookings Papers on Economic Activity, Issue no. 1:137-99.

Clayton, T., C. Criscuolo, P. Goodridge, and K. Waldron. 2004. Enterprise ecommerce: Measurement and impact. In The economic impact of ICT, ed. D. Pilat, 241-60. Paris: Organization for Economic Cooperation and Development.

Cooper, R., J. Haltiwanger, and L. Power. 1999. Machine replacement and the business cycle: Lumps and bumps. American Economic Review 89 (5): 921-46.

Criscuolo, C., J. E. Haskel, and M. J. Slaughter. 2005. Global engagement and the innovation activities of firms. NBER Working Paper no. 11479. Cambridge, MA: National Bureau of Economic Research.

Dedrick, J., V. Gurbaxani, and K. Kraemer. 2003. Information technology and economic performance: A critical review of the empirical evidence. ACM Computing Surveys 35 (1): 1-28.

Doms, M. 1996. Estimating capital efficiency schedules within production functions. Economic Inquiry 34 (1): 78-92.

Doms, M., T. Dunne, and K. Troske. 1997. Workers, wages, and technology. The Quarterly Journal of Economics 112 (1): 253-90.

Dunne, T., L. Foster, J. Haltiwanger, and K. Troske. 2000. Wage and productivity dispersion in U.S. manufacturing: The role of computer investment. NBER Working Paper no. 7465. Cambridge, MA: National Bureau of Economic Research.

Dunne, T., J. Haltiwanger, and K. R. Troske. 1997. Technology and jobs: Secular changes and cyclical dynamics. Carnegie-Rochester Conference Series on Public Policy 46 (June): 107-48.

Dunne, T., and J. A. Schmitz, Jr. 1995. Wages, employment structure and employer size-wage premia: Their relationship to advances-technology usage at U.S. manufacturing establishments. Economica 62 (245): 89-107.

Greenan, N., J. Mairesse, and A. Topiol-Bensaid. 2001. Information technology and research and development impacts on productivity and skills: Looking for correlations on French firm level data. NBER Working Paper no. 8075. Cambridge, MA: National Bureau of Economic Research, January.

Griliches, Z. 1994. Productivity, R\&D, and the data constraint. American Economic Review 84 (1): 1-23.

Griliches, Z., and J. Mairesse. 1995. Production functions: The search for identification. In Practicing econometrics: Essays in method and application, ed. Zvi Griliches, 383-411. Cheltenham, UK: Edgar Elgar, 1998.

Haltiwanger, J., and R. Jarmin. 2000. Measuring the digital economy. In Understanding the digital economy, ed. E. Brynjolfsson and B. Kahin, 13-33. Cambridge, MA: MIT Press. 
Haltiwanger, J., R. Jarmin, and T. Schank. 2003. Productivity, investment in ICT and market experimentation: Micro evidence from Germany and the U.S. Center for Economic Studies Discussion Papers in Economics no. CES-03-06. Washington, DC: U.S. Bureau of the Census, February.

Jorgenson, D., M. Ho, and K. Stiroh. 2005. Growth of U.S. industries and investments in information technology and higher education. In Measuring capital in the new economy, ed. C. Corrado, J. Haltiwanger, and D. Sichel, 403-78. Studies in Income and Wealth, vol. 65. Chicago: University of Chicago Press.

Jorgenson, D. W., and K. J. Stiroh. 2000. Industry-level productivity and competitiveness between Canada and the United States. American Economic Review 90 (May): 161-67.

McGuckin, R. H., M. L. Streitwieser, and M. E. Doms. 1998. The effect of technology use on productivity growth. Economic Innovation and New Technology Journal, 7 (October): 1-26.

Mesenbourg, T. 2001. Measuring electronic business. http://www.census.gov/estats.

Motohashi, K. 2001. Economic analysis of information network use: Organizational and productivity impacts on Japanese firms. METI Research and Statistics Department Working Paper. Tokyo: METI, January.

- 2003. Firm-level analysis of information network use and productivity in Japan. Paper presented at Comparative Analysis of Enterprise Data (CAED) conference, London.

Oliner, S. D., and D. E. Sichel. 2000. The resurgence of growth in the late 1990s: Is information technology the story? Journal of Economic Perspectives 14 (4): 3-22.

Pilat, D., ed. 2004. The economic impact of ICT. Paris: Organization for Economic Cooperation and Development.

Power, L. 1998. The missing link: Technology, investment, and productivity. Review of Economics and Statistics 80 (2): 300-313.

Schreyer, P. 1999. OECD manual on productivity measurement: A guide to the measurement of industry-level and aggregate productivity growth. Paris: Organization for Economic Cooperation and Development.

Stiroh, K. J. 2004. Reassessing the impact of IT in the production function: A metaanalysis. New York: Federal Reserve Bank of New York.

Stolarick, K. M. 1999a. Are some firms better at IT? Differing relationships between productivity and IT spending. Center for Economic Studies Working Paper no. 99-13. Washington, DC: U.S. Bureau of the Census.

- 1999b. IT spending and firm productivity: Additional evidence from the manufacturing sector. Center for Economic Studies Working Paper no. 99-10. Washington, DC: U.S. Bureau of the Census.

Triplett, J., and B. Bosworth. 2003. Baumol's disease has been cured: IT and multifactor productivity in U.S. services industries. Federal Reserve Bank of New York Economic Policy Review 9 (3): 23-33.

U.S. Census Bureau. 2001. General summary: 1997 Economic Census, manufacturing. http://www.census.gov/prod/ec97/97m31s-gs.pdf. 2002. E-stats. http://www.census.gov/estats.

Wilson, D. 2004. Productivity and capital heterogeneity: A firm-level analysis. Federal Reserve Bank of San Francisco. Unpublished Mimeograph. 